\title{
Developing an Assessment-of-Clinical-Exodontia-Skills (ACES) Rating Scale for Undergraduate Dental Students
}

\author{
Omer Sefvan Janjua1, Abid Ashar² and Tanzeela Khalid3
}

\begin{abstract}
Objective: To develop assessment-of-clinical-exodontia-skills (ACES) rating scale for formative and summative assessment of undergraduate dental students performing exodontia.

Place and Duration of Study: Faisalabad Medical University, Faisalabad, from May 2017 to February 2018.

Methodology: A preliminary scale was developed using literature search and informal discussion with experts. In the first round of Delphi, this scale was emailed to oral surgery faculty across Pakistan. Their opinions were sought and the form was modified accordingly. In the second round, the modified form was emailed again to the respondents of first round and thus the form was finalized by obtaining their comments on the modified form.

Results: A preliminary 27-point round-1 questionnaire was sent to 42 experts. Out of these, 30 responded (overall response rate $71.4 \%$ ) and the form was modified according to their response. Frequency, percentage, and mean of Likertbased responses was calculated along with thematic analysis of individual responses. In round 2, the modified form was sent to the 30 respondents of round 1 . Out of these, 21 replied (response rate $70 \%$ ) and form was further modified accordingly. In round 2, primary focus was on marking/scoring strategy.

Conclusion: ACES form was developed, which can be important tool in assessing exodontia skills of undergraduate dental students. This needs practical application and testing for validity.
\end{abstract}

Key Words: Tooth extraction, Dental students, Educational measurement.

\section{INTRODUCTION}

Acquisition of procedural skills and display of working knowledge is a mandatory requirement for a dental student. ${ }^{1}$ Exodontia or removal of tooth is a core competency that a dental student must be adept in, i.e. he/she must possess sufficient knowledge, skill, and attitude for the procedure. ${ }^{2}$ According to Miller, exodontia is placed at the level of "Does" for the undergraduate students as they have to perform a tooth extraction in their final professional examination. ${ }^{3}$ In order to reach that level, they are rotated in the oral surgery department during their third and final years where they learn to perform various steps associated with the procedure of tooth extraction.

Every institution has its own way of assessing students performing exodontia. ${ }^{4}$ Most of the dental schools in United Kingdom use OSCE or a checklist-based formative assessment tool such as structured clinical operative test (SCOT) or a checklist assessment of

1 Department of Oral and Maxillofacial Surgery, Faisalabad Medical University, Faisalabad, Pakistan

2 Department of Oral and Maxillofacial Surgery, Fatima Memorial College of Dentistry, Lahore, Pakistan

3 Department of Dermatology and Medical Education, University Medical and Dental College, Faisalabad, Pakistan Correspondence: Dr. Omer Sefvan Janjua, Department of Oral and Maxillofacial Surgery, Faisalabad Medical University, Allied Hospital, Faisalabad, Pakistan

E-mail:osj1982@hotmail.com

Received: September 04, 2018; Accepted: December 21, 2018 operative skills (CAOS). ${ }^{5}$ In most of the dental colleges in Pakistan, the students are observed by the faculty and are required to maintain a log book of nature of procedure performed, which is signed by a faculty member later on. No such formal checklist-based assessment system is in place. The log book fails to represent the actual competency a student has achieved, and there is a deficiency of formal feedback towards the student's performance. 6 This lack of feedback and inadequate workplace-based assessment result in unsatisfactory performance in the final examinations.

The objective of this study was to develop a rating scale by consensus of faculty of oral surgery (Delphi technique), which can assess students on a universally accepted scale and apprise them of their true competence. Once developed, the scale will be available to the faculty members/institutes for assessing the competence of their students in exodontia, both formatively as well as summatively.

\section{METHODOLOGY}

A 2-round Delphi technique was employed with a concurrent mixed method study design. In order to develop an exodontia rating form, literature search and an informal discussion with a panel of three experts was done to formulate a preliminary rating scale. All the faculty members of oral surgery (Assistant Professors and above) working in institutes across Pakistan were included in the study. Oral surgeons, not appointed as faculty in teaching institutes, were excluded from the study. In the first round, preliminary rating scale along 
with a brief background/introduction of the study was shared with the oral surgery faculty through emails in the form of a questionnaire to get their input regarding face and construct validity of the instrument. The questionnaire comprised of 27 Likert-based responses and columns for individual responses by the experts. Follow-up through reminder emails, calls and messages for return of Delphi round 1 survey forms was done. The data collected in Delphi round 1 was analysed and preliminary scale was modified by incorporating valid suggestions received from experts. In the round 2, the modified form was shared through email with the respondents of round 1 to get a consensus on the final form.

The data thus gathered were analysed using SPSS version 20. Frequency was calculated for number of responders. Since it was a mixed type questionnaire, the Likert-based responses were analysed; and we calculated mean and standard deviation of the individual responses. For the qualitative component of the form, thematic analysis was done. Finally, a statistical average of the final opinion of experts was calculated.

\section{RESULTS}

In Delphi round 1, a 27-point questionnaire was sent to a total of 42 subject experts all over the country. Out of these 42, 30 experts replied to the questionnaire with an overall response rate of $71.4 \%$. Teaching experience of the experts ranged from 6 months to 25 years with a mean of $7.758 \pm 6.94$ years. Experts who responded included 8 professors (26.7\%), 4 associate professors, $(13.3 \%)$ and 18 assistant professors (60\%).

The preliminary questionnaire that was shared in round 1 was a mixed type questionnaire consisting of individual 27 Likert scale-based rating questions (quantitative component) and columns for individual qualitative responses from the expert. The questions were based on sub-competencies that the authors considered vital for a student performing exodontia. The experts were asked to highlight whether in their opinion those subcompetencies were highly important, important, unimportant, not required at all or if they were undecided about them. They were also requested to add any competency which according to them would be vital for the assessment of final year student performing tooth extraction. Thematic analysis of individual responses was done and the results are shown in Table I. Five themes emerged as following universal precautions, rate of position of local anesthesia, using aspirating syringe for local anesthesia, knowledge about procedural complications and tooth luxation and delivery.

The questionnaire of round 1 was modified according to the comments of the experts and the modified questionnaire was sent to the 30 respondents of round 1 . Out of these 30,21 experts responded to round 2 questionnaire (overall response rate for round 2 was $70 \%$ ).

Table I: Showing overall results of Delphi round 1 .

\begin{tabular}{|c|c|c|c|c|c|c|}
\hline Question & Highly important & Important & Undecided & Un-important & $\begin{array}{c}\text { Not required } \\
\text { at all }\end{array}$ & Mean score \\
\hline Greets and Introduces oneself & $19(63.3 \%)$ & $11(36.7 \%)$ & - & - & - & 4.93 \\
\hline Acquires informed consent & $28(93.3 \%)$ & $2(6.7 \%)$ & - & - & - & 4.63 \\
\hline Acquisition of proper history & $25(83.3 \%)$ & $5(16.7 \%)$ & - & - & - & 4.83 \\
\hline Performs pertinent clinical examination & $24(80 \%)$ & $6(20 \%)$ & - & - & - & 4.80 \\
\hline Dons personal protective equipment & $22(73.3 \%)$ & $7(23.3 \%)$ & $1(3.3 \%)$ & - & - & 4.70 \\
\hline Employs aseptic technique & $23(76.7 \%)$ & $6(20 \%)$ & $1(3.3 \%)$ & - & - & 4.73 \\
\hline Positions patient properly & $18(60 \%)$ & $12(40 \%)$ & - & - & - & 4.60 \\
\hline Positions oneself properly according to the tooth & $17(56.7 \%)$ & $9(30 \%)$ & $3(10 \%)$ & $1(3.3 \%)$ & - & 4.40 \\
\hline Selects correct instruments & $24(80 \%)$ & $6(20 \%)$ & - & - & - & 4.80 \\
\hline Places instruments correctly & $7(23.3 \%)$ & $22(73.3 \%)$ & $1(3.3 \%)$ & - & - & 4.20 \\
\hline Chooses type of local anesthesia correctly & $21(70 \%)$ & $9(30 \%)$ & - & - & - & 4.70 \\
\hline Checks expiry date of the cartridge & $21(70 \%)$ & $7(23.3 \%)$ & $1(3.3 \%)$ & $1(3.3 \%)$ & - & 4.60 \\
\hline Loads syringe properly & $10(33.3 \%)$ & $14(46.7 \%)$ & $5(16.7 \%)$ & $1(3.3 \%)$ & - & 4.10 \\
\hline Knowledgeable of relevant anatomy & $27(90 \%)$ & $3(10 \%)$ & - & - & - & 4.90 \\
\hline Deposits anesthetic solution and needle withdrawal & $19(63.3)$ & $9(30 \%)$ & $2(6.7 \%)$ & - & - & 4.57 \\
\hline Asks about change in sensation & $9(30 \%)$ & $21(70 \%)$ & - & - & - & 4.30 \\
\hline Performs gingival probing to assess local anesthesia & $19(63.3 \%)$ & $11(36.7 \%)$ & - & - & - & 4.63 \\
\hline Reassures patient about pain/pressure & $16(53.3 \%)$ & $14(46.7 \%)$ & - & - & - & 4.53 \\
\hline Knows adjunctive measures in case of failure of anesthesia & $15(50 \%$ & $15(50 \%)$ & - & - & - & 4.50 \\
\hline Ensures correct tooth & $28(93.3 \%)$ & $2(6.7 \%)$ & - & - & - & 4.93 \\
\hline Uses periosteal elevator properly & $14(46.7 \%)$ & $15(50 \%)$ & $1(3.3 \%)$ & - & - & 4.40 \\
\hline Properly uses Coupland's elevator where needed & $17(56.7 \%)$ & $10(33.3 \%)$ & $3(10 \%)$ & - & - & 4.47 \\
\hline Applies forceps properly & $22(73.3 \%)$ & $8(26.7 \%)$ & - & - & - & 4.73 \\
\hline Retracts and supports jaw correctly & $20(66.7 \%)$ & $10(33.3 \%)$ & - & - & - & 4.67 \\
\hline Performs adequate care of the socket & $23(76.7 \%)$ & $7(23.3 \%)$ & - & - & - & 4.77 \\
\hline Gives postoperative instructions & $25(83.3 \%)$ & $5(16.7 \%)$ & - & - & - & 4.83 \\
\hline Prescribes medicines appropriately & $15(50 \%)$ & $13(43.3 \%)$ & $2(6.7 \%)$ & - & - & 4.43 \\
\hline
\end{tabular}


Table II: Showing results of Delphi round 2.

\begin{tabular}{|c|c|c|c|}
\hline Sub-competency & Mandatory & No. & Percentage \\
\hline Greets and introduces oneself & 16 & 05 & $76.2 \%$ \\
\hline Takes pertinent history & 20 & 01 & $95.2 \%$ \\
\hline Performs clinical examination & 17 & 04 & $81 \%$ \\
\hline Advises and interprets radiographs & 05 & 16 & $23.8 \%$ \\
\hline Develops diagnosis & 11 & 10 & $52.4 \%$ \\
\hline Takes informed consent & 14 & 07 & $66.7 \%$ \\
\hline Wears PPE & 13 & 08 & $61.9 \%$ \\
\hline Maintains asepsis and follows universal precautions throughout the procedure & 17 & 04 & $81 \%$ \\
\hline Knows the anatomical landmarks for anesthesia administration & 17 & 04 & $81 \%$ \\
\hline Correct choice and dosage of LA & 13 & 08 & $61.9 \%$ \\
\hline Checks expiry of cartridge & 05 & 16 & $23.8 \%$ \\
\hline Positions oneself properly for LA administration & 19 & 02 & $90.5 \%$ \\
\hline Employs proper technique for LA & 21 & - & $100 \%$ \\
\hline Re-sheathing and securing of needle & 04 & 17 & $19 \%$ \\
\hline Confirms successful LA by gingival probing & 15 & 06 & $71.4 \%$ \\
\hline Reassures patient regarding pain and pressure & 07 & 14 & $33.3 \%$ \\
\hline Knows adjunctive measures in case of failure of LA & 18 & 03 & $85.7 \%$ \\
\hline Ensures correct tooth & 17 & 04 & $81 \%$ \\
\hline Positions oneself properly for extraction & 08 & 13 & $38.1 \%$ \\
\hline Arranges armamentarium properly & 04 & 17 & $19 \%$ \\
\hline Properly applies periosteal elevator & 20 & 01 & $95.2 \%$ \\
\hline Properly applies Coupland's elevator (where needed) & 20 & 01 & $95.2 \%$ \\
\hline Properly applies forceps & 20 & 01 & $95.2 \%$ \\
\hline Properly retracts and supports jaw & 21 & - & $100 \%$ \\
\hline Luxates and delivers tooth & 21 & - & $100 \%$ \\
\hline Knowledgeable about complications of exodontia & 10 & 11 & $47.6 \%$ \\
\hline Gives proper postop instructions & 20 & 01 & $95.2 \%$ \\
\hline Takes care of the extraction socket & 15 & 06 & $71.4 \%$ \\
\hline Prescribes adequate postop medication & 12 & 09 & $57.1 \%$ \\
\hline
\end{tabular}

Table III: Showing components and marks distribution as advised by the experts.

\begin{tabular}{l|c|c|c|c|c}
\hline Component & $\begin{array}{c}\text { Percentage } \\
\text { Marks } \\
\text { (Minimum) }\end{array}$ & $\begin{array}{c}\text { Percentage } \\
\text { Marks } \\
\text { (Maximum) }\end{array}$ & Mean & $\begin{array}{c}\text { Standard } \\
\text { Deviation }\end{array}$ & $\begin{array}{c}\text { Standard } \\
\text { Error }\end{array}$ \\
\hline Preoperative assessment & 10 & 20 & 14.29 & 3.96 & 0.86 \\
\hline Cross-infection control & 0 & 15 & 10.95 & 3.74 & 0.81 \\
\hline Local anesthesia & 25 & 35 & 29.29 & 3.27 & 0.71 \\
\hline Extraction & 30 & 45 & 35.95 & 4.90 & 1.07 \\
\hline $\begin{array}{l}\text { Postoperative instructions } \\
\text { and medication }\end{array}$ & 5 & 20 & 9.76 & 4.02 & 0.87 \\
\hline
\end{tabular}

Two rating scales for assessment were considered and the experts were asked to decide which scale was better in their opinion for assessment of students. First scale comprised of 4 categories: $\mathrm{G}=$ good, $\mathrm{S}=$ satisfactory, $\mathrm{U}=$ unsatisfactory, and $\mathrm{N} / \mathrm{O}=$ not observed. The second scale comprised of 5 points: $5=$ excellent, $4=$ good, 3 =satisfactory, 2=unsatisfactory, 1=poor, N/O=not observed. Out of 21,5 experts $(23.8 \%)$ favoured GSU scale while the rest 16 experts $(76.2 \%)$ suggested the 5-Point Likert-scale.

In the questionnaire of round 2, the experts were asked to determine sub-competencies which in their opinion were absolutely necessary in order to declare a candidate successful in their assessment. The results of these responses are shown in Table II.

The questionnaire was divided into five segments namely; preoperative assessment, cross-infection control, local anesthesia, extraction, and postoperative instruction. The experts were also asked to assign weightage to each component so that marking scheme could be finalised. The results are shown in Table III.

\section{DISCUSSION}

Assessment of exodontia is a vital part of the dental undergraduate curriculum. ${ }^{7,8}$ There is a paradigm shift in modern day education from knowledge to competency. Hence, the objective of this study was to develop a rating scale which can be used to assess the clinical competence of dental students performing tooth extractions. ${ }^{9}$

Delphi technique is an iterative process of gathering information and judgements through series of rounds/ questionnaires distributed among experts till a consensus is reached. ${ }^{10,11}$ In this study, a preliminary form was circulated among the subject experts and their opinions were sought; and the form was modified and recirculated so that it could be finalised. The participation of the experts was voluntary and complete confidentiality and anonymity was maintained.

A systematic process of questionnaire development was followed as mentioned in the AMEE guidelines. ${ }^{12,13} \mathrm{~A}$ literature review followed by an informal discussion among the two experts and the principal investigator was conducted to develop the preliminary questionnaire, 
Assessment-of-Clinical-Exodontia-Skills (ACES)

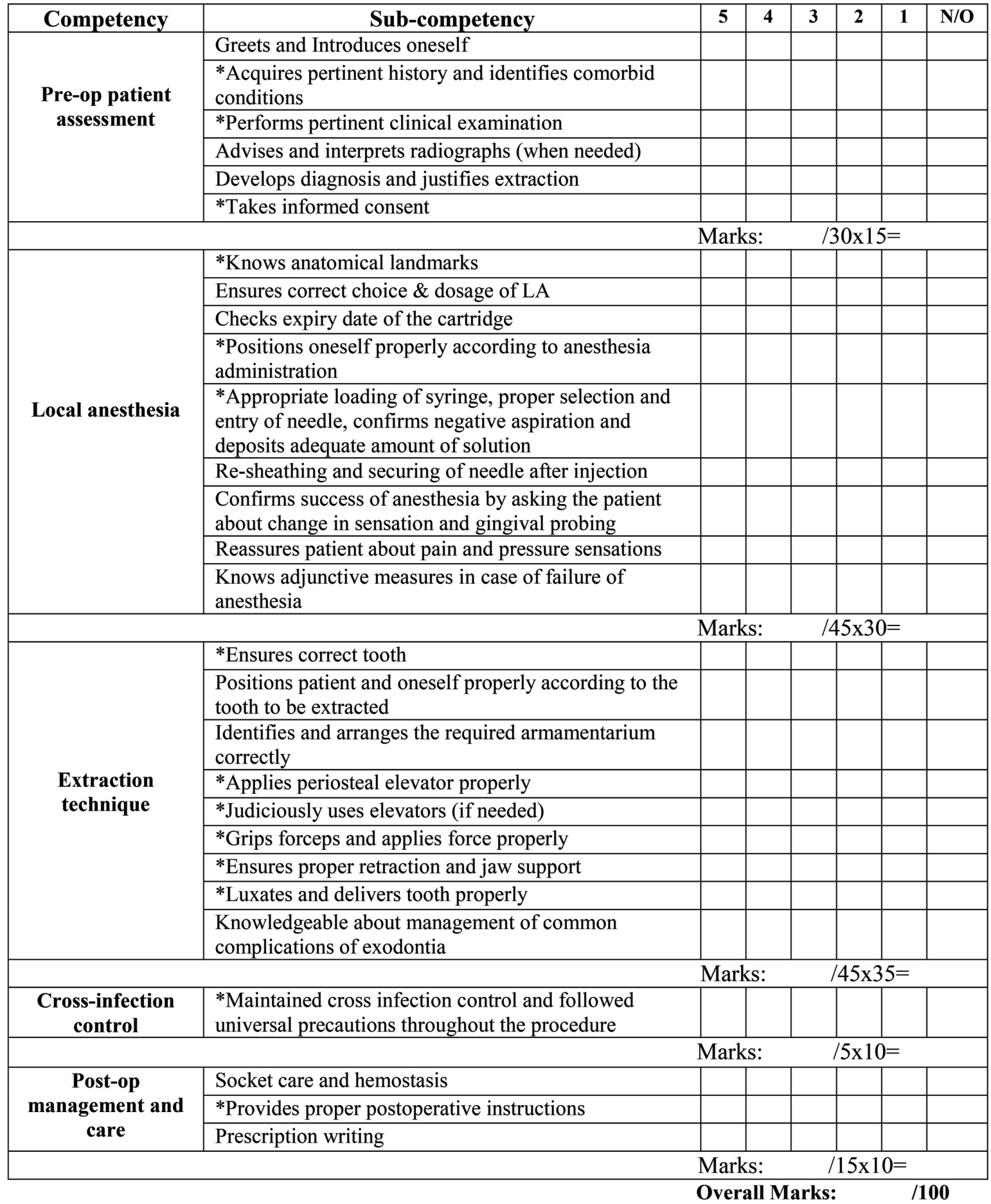

Decision of the examiner: Pass/Fail/Borderline

Feedback Comments:

Date:

Signature:

Key: $5=$ Excellent, 4=Good, 3=Satisfactory, $2=$ Unsatisfactory, $1=$ Poor, $N / O=$ Not Observed .

*Marks the sub-competency considered mandatory for the candidate to pass.

Figure 1: ACES form. 
which was sent to subject experts for validation. One of the most vital elements in Delphi study is identifying 'experts' who should be the specialist of the field. ${ }^{14}$ In this study, the experts were identified as those faculty members who were directly involved in the undergraduate teaching and training and were working as Professors, Associate Professors or Assistant Professors of oral surgery across dental institutes of Pakistan. An overall response rate of $71.4 \%$ was received in round 1 and $70 \%$ in round 2 . An almost similar response rate has been reported by Elwyn et al. in their Delphi study. ${ }^{15}$

Opinion-based Likert scales are commonly employed in healthcare as well as educational research. Data is gathered on these questionnaire followed by content analysis. ${ }^{16}$ In this study, both quantitative and qualitative data were generated. Quantitative content analysis was done and individual frequency and mean score was calculated for each response. Following the concept of statistical average in Delphi studies, ${ }^{17}$ all those subcompetencies were retained in the form whose mean score was above 4 because it meant that they were considered important or highly important by the experts.

Qualitative content analysis is a systematic process for identifying themes and phenomenon in research. 18 Three approaches for thematic analysis have been described in literature by Hsieh et al., namely conventional, directed and summative. 19 The authors employed conventional approach and deducted themes/codes directly from text data, and which were later incorporated in the round 2 form.

In round 2, the major focus was on marking scheme and overall marks distribution. Two scoring scales were suggested: GSU (good, satisfactory and unsatisfactory), and a five-point Likert scale ( $5=$ excellent, $4=$ good, $3=$ satisfactory, $2=$ unsatisfactory, $1=$ poor). Majority of the experts $(76.2 \%)$ were in favour of the 5-Point Likert. Hence, it was selected as final scoring scale in the proforma.

The experts were asked to highlight sub-competencies in the form which they considered absolutely necessary for a candidate to perform satisfactorily in order to be declared successful. The sub-competencies, about which more than $80 \%$ of the experts suggested as mandatory, were marked with an $\left(^{*}\right)$ in the final form. It was decided that any student performing unsatisfactorily or poorly in these mandatory competencies will be considered fail despite his/her overall score.

The final question that was asked from the experts was marks distribution. The form was divided into five components for this purpose: preoperative assessment, cross infection control, local anaesthesia, extraction and post-op instructions, and medications. These subcomponents have also been pointed out by MacLuskey et al. 5 According to the weightage of each component in exodontia, the experts were asked to assign marks weightage to each component. Final mean score was rounded off to the nearest whole number. As a result, $15 \%$ marks were assigned to preoperative assessment, $10 \%$ were assigned to cross-infection control, $30 \%$ to local anaesthesia administration, 35\% to extraction and $10 \%$ to postoperative instructions and medication. Final score will be a sum total of all the scores acquired in each component. A candidate attaining 50 or $60 \%$ (depending upon the passing criteria of individual institute) of the total score will be declared pass provided he/she is awarded at least satisfactory score in the mandatory competencies.

The final scale that emerged as a result of this study was named as ACES form (Figure 1), and it is attached as appendix for future use and validation purposes. Since it was a Delphi technique-based study, hence all the limitations of a Delphi approach mentioned in literature applies to this research as well. $14,17,20$ Some of these include forced or intuitive judgement from the experts, relatively low reliability, inability to reach a true consensus and biased results subject to ambiguity in questionnaire. The authors tried their best to minimise these limitations as humanly possible.

One limitation, particular to the study, was that the authors were able to achieve face and content validity of this tool; but the criterion and construct validity along with inter-rater reliability still needs to be carried out. ${ }^{21}$ So, future research is still needed in order to get the form tried and tested before it can become a part of the assessment process throughout the country.

\section{CONCLUSION}

Assessment of clinical skills is a vital requirement for students. The ACES scale, developed as a result of this study, can be a useful tool for formative as well as summative assessment of undergraduate dental students. However, it has to be validated before it can be put into use.

\section{REFERENCES}

1. Kundra S, Singh T. Feasibility and acceptability of direct observation of procedural skills to improve procedural skills. Indian Pediatr 2014; 51:59-60.

2. Dantas AK, Shinagawa A, Deboni MC. Assessment of preclinical learning on oral surgery using three instructional strategies. J Dent Educ 2010; 74:1230-6.

3. Durham JA, Moore UJ, Corbett IP, Thomson PJ. Assessing competency in dentoalveolar surgery: A 3-year study of cumulative experience in the undergraduate curriculum. Eur $J$ Dent Educ 2007; 11:200-7.

4. Macluskey M, Durham J. Oral surgery undergraduate teaching and experience in the United Kingdom: A national survey. Eur J Dent Educ 2009; 13:52-7.

5. Macluskey M, Hanson C, Kershaw A, Wight AJ, Ogden GR. Development of a structured clinical operative test (SCOT) in the assessment of practical ability in the oral surgery undergraduate curriculum. Br Dent J 2004; 196:225-8. 
6. Fatemah K, Alavinia SM. Students' perception about logbooks: Advantages, limitation and recommendation - A qualitative study. J Pak Med Assoc 2012; 62:1184-6.

7. Brand HS, van der Cammen CCJ, Roorda SME, Baart JA. Tooth extraction education at dental schools across Europe. BDJ Open 2015; 1:15002

8. Omar E. Perceptions of teaching methods for preclinical oral surgery: A comparison with learning styles. Open Dent $J$ 2017; 11:109-19

9. Redford R, Durkan C, Sivarajsingham V, Emanuel C. Students perception of exodontia competency assessment in a UK dental school. Eur J Dent Educ 2018; 22:92-100

10. Boulkedid R, Abdoul H, Loustau M, Sibony O, Alberti C. Using and reporting the Delphi method for selecting healthcare quality indicators: A systematic review. Public Lib Sci One 2011; 6:e20476

11. Skulmoski GJ, Hartman FT, Krahn J. The Delphi method for graduate research. J Info Tech Educ Res 2007; 6:1-21.

12. Artino AR, Jeffrey SLR, Dezee KJ, Gehlbach H. Developing questionnaire for educational research: AMEE guide No. 87. Med Teach 2014; 36:463-74.

13. Burford B, Hesketh A, Wakeling J, Bagnall G, Colthart I, Illing J, et al. Asking the right questions and getting meaningful responses: 12 tips on developing and administering a questionnaire survey for healthcare professionals. Med Teach 2009; 31:207-11.

14. Keeney S, Hasson F, McKenna HP. A critical review of the Delphi technique as a research methodology for nursing. Int $J$ Nurs Stud 2001; 38:195-200.

15. Elwyn G, O'Connor A, Stacey D, Volk R, Edwards A, Coulter A, et al. Developing a quality criteria framework for patient decision aids: online international Delphi consensus process. Br Med J 2006; 333:417.

16. Barua A. Methods for decision-making in survey questionnaires with continuous variables. Educ Res J 2013; 3:47-9

17. Yousuf MI. Using experts' opinions through Delphi technique. Practical Assessment Res Eval 2007; 12:1-8.

18. Elo S, Kaariainen M, Kanste O, Polkki T, Utriainen K, Kyngas H. Qualitative content analysis: A focus in trustworthiness. Sage Open 2014:1-10

19. Hsieh HF, Shannon SE. Three approaches to qualitative content analysis. Qual Health Res 2005; 15:1277-88.

20. de Meyrick J. The Delphi method and health research. Health Educ 2003; 103:7-16.

21. Cook DA, Hatala R. Validation of educational assessments: A primer for simulation and beyond. Adv in Simul 2016; 1:31.

.......... 